\title{
Effect of a Peroxynitrite Scavenger, a Manganese-Porphyrin Compound on Airway Remodeling in a Murine Asthma
}

\author{
Yang Cao, ${ }^{a}$ Masanori Fujii, ${ }^{a}$ Keiichi Ishihara, ${ }^{b}$ Satoshi Akiba, ${ }^{b}$ Hiroyuki Yasui, ${ }^{c}$ and \\ Takeshi Nabe*,a \\ ${ }^{a}$ Department of Pharmacology, Kyoto Pharmaceutical University; ${ }^{b}$ Department of Pathological Biochemistry, \\ Kyoto Pharmaceutical University; and ${ }^{c}$ Department of Analytical and Bioorganic Chemistry, Kyoto Pharmaceutical \\ University; 5 Nakauchi, Misasagi, Yamashina, Kyoto 607-8414, Japan. \\ Received September 13, 2012; accepted February 14, 2013; advance publication released online February 25, 2013
}

\begin{abstract}
Airway remodeling, pathological changes in the lung structure, is a characteristic feature of chronic asthma. The changes include bronchial epithelial hyperplasia and hypertrophy, excess production of mucus, and fibroblast proliferation in the lung. On the other hand, it has been known that both nitric oxide and superoxide anion are increased in exhaled air of asthmatic patients. These molecules react with each other forming a powerful oxidant, peroxynitrite. In this study, effect of a peroxynitrite scavenger, a metalloporphyrin compound, [tetrakis(4-carboxylatophenyl)porphyrinato]manganese(III) (MnTBAP) on multiple antigen challenge-induced airway remodeling was evaluated in mice. When sensitized BALB/c mice were intratracheally challenged with an antigen, ovalbumin, for 3 times, bronchial epithelial thickening and mucus accumulation in the epithelium were histologically observed. Daily treatment with MnTBAP (3, $10 \mathrm{mg} / \mathrm{kg} /$ time/twice a day, intraperitoneally (i.p.)) dose-dependently suppressed both the epithelial thickening and mucus accumulation in the epithelium. On the other hand, terminal deoxynucleotidyl transferase-mediated deoxyuridine triphosphate nick-end labeling (TUNEL) staining revealed that the multiple antigen challenges increased the number of apoptotic cells in the bronchial epithelium. The increase in apoptotic cells was also effectively suppressed by the treatment with MnTBAP. Taken together, it was suggested that peroxynitrite could be involved in the formation of epithelial hyperplasia associated with the mucus accumulation through induction of apoptosis of the epithelial cells. Thus, peroxynitrite can be a target molecule for development of new pharmacotherapy for asthma.
\end{abstract}

Key words asthma; airway remodeling; peroxynitrite; epithelial cell; apoptosis

Airway remodeling, one of characteristic features of chronic asthma, is structural lung changes including epithelial hyperplasia and hypertrophy, mucus hyperproduction and fibroblast proliferation. ${ }^{1,2)}$ These structural modifications thicken airway walls in asthma patients, leading to airway hyperresponsiveness to specific allergens and non-specific stimuli. ${ }^{1)}$ Recent studies have suggested that mechanisms underlying airway remodeling in asthma include not only acquired immune responses being organized mainly by Th2 cells, but also innate immune responses being triggered by bronchial epithelial cell activation, ${ }^{3,4)}$ whereas detailed mechanisms have not clearly defined.

It has been well known that both nitric oxide (NO) and superoxide anion $\left(\mathrm{O}_{2}^{-}\right)$are increased in exhaled air of asthmatic patients. ${ }^{5,6)}$ These two molecules react to each other without any enzymes to form a powerful oxidant, peroxynitrite $\left(\mathrm{ONOO}^{-}\right)$, which nitrates various proteins to disrupt the physiological cellular functions, leading to cellular apoptosis. ${ }^{7)}$ On the other hand, there was a greater level of apoptotic activity in the airway biopsy in subjects with severe asthma as compared with normal subjects. ${ }^{8)}$ Considering these findings, peroxynitrite possibly plays significant roles in the induction of epithelial cell apoptosis, which is closely associated with the development of airway remodeling. However, roles of peroxynitrite in airway remodeling process in asthma have been unclear.

We have recently reported that multiple intratracheal challenges with an antigen ovalbumin (OVA) induced development

The authors declare no conflict of interest of airway remodeling, bronchial epithelial thickening, mucus accumulation in the epithelium and subepithelial fibrosis, ${ }^{9}{ }^{9}$ in Balb/c mice. ${ }^{10,11)}$ The development of airway remodeling required relatively short period compared to other murine asthma models, in which antigen challenges were carried out by intranasal instillation of OVA solution or exposure to OVA mist in sensitized BALB/c mice. ${ }^{12,13)}$ The lung histological changes in our murine asthma model were significantly suppressed by daily treatment with a glucocorticoid, dexamethasone, ${ }^{9)}$ whereas cellular and molecular mechanisms underlying the development of airway remodeling have not been clear.

In this study, in order to know whether peroxynitrite is involved in the development of airway remodeling, we used a peroxynitrite scavenger, [tetrakis(4-carboxylatophenyl)porphyrinato]manganese(III) (MnTBAP), which has been reported to specifically eliminate peroxynitrite in not only in vitro but also in vivo experiments. ${ }^{14-16)}$ Here, we evaluated (1) whether successive treatment with MnTBAP exerts inhibition on the development of airway remodeling in the murine model of asthma, and (2) whether the inhibition by MnTBAP is associated with effect on excessive apoptosis of the airway epithelial cells.

\section{MATERIALS AND METHODS}

Sensitization and Challenge Six-week-old BALB/c mice were purchased from Japan SLC (Hamamatsu). As previously reported by us, ${ }^{9-11)}$ the mice were sensitized by intraperitoneal (i.p.) injections with ovalbumin (OVA, Grade V; Sigma Chem., St. Louis, MO, U.S.A.) adsorbed to $\mathrm{Al}(\mathrm{OH})_{3}$ at a dose of $50 \mu \mathrm{g}$ 
OVA adsorbed to $2 \mathrm{mg} \mathrm{Al}(\mathrm{OH})_{3} / 0.5 \mathrm{~mL}$ phosphate buffered saline (PBS)/animal on days 0,14 and 28. The sensitized mice were challenged on day 35, 36 and 37 under inhalation anesthesia with isoflurane (Abbott Japan, Tokyo, Japan) with 2\% OVA at a volume of $25 \mu \mathrm{L}$ by intratracheal administration, as reported previously. ${ }^{17)}$ This animal study was approved by the Experimental Animal Research Committee at Kyoto Pharmaceutical University.

Treatment with MnTBAP MnTBAP chloride (Enzo Life Sciences, Farmingdale, NY, U.S.A.) or the vehicle, PBS was i.p. administered twice a day on day $35,36,37,38$ and 39 at a dose of 3 or $10 \mathrm{mg} / \mathrm{kg} / \mathrm{time}$. On days of antigen challenge (day $35,36,37)$, MnTBAP or PBS was administered $4 \mathrm{~h}$ before and $6 \mathrm{~h}$ after respective challenges. In addition, the last dosing was conducted $4 \mathrm{~h}$ before sacrificing mice on day 40 .

Histopathological Study Before the $1 \mathrm{st}$ and $72 \mathrm{~h}$ after the 3rd OVA challenges, the left lobe of the lung was isolated under anesthetization with ketamine and xylazine, and then fixed with $10 \%$ buffered formalin. Tissues were embedded in paraffin, and $4-\mu \mathrm{m}$ sections were stained with hematoxylin and eosin, and periodic acid-Schiff (PAS) for light microcopic observation as previously described. ${ }^{9)}$ The degree of epithelial thickening was quantified using PAS-stained sections. ${ }^{9)}$ Briefly, the degree of epithelial thickening was expressed by dividing the epithelial area $\left(\mu \mathrm{m}^{2}\right)$ by the length $(\mu \mathrm{m})$ of the basement membrane around a bronchus, the diameter of which was $200-400 \mu \mathrm{m}$. Mucus accumulation in the epithelial layer was also quantified using PAS-stained sections by dividing the $\mathrm{PAS}^{+}$area in the epithelium $\left(\mu \mathrm{m}^{2}\right)$ by the length of the basement membrane $(\mu \mathrm{m}){ }^{9)}$

Analysis of Leukocytes in Bronchoalveolar Lavage Fluid (BALF) Before the 1st challenge and $72 \mathrm{~h}$ after the 3rd OVA challenges, the lung was lavaged via a tracheal catheter using two aliquots of $0.8 \mathrm{~mL}$ PBS containing $2 \%$ fetal bovine serum under anesthetization with ketamine and xylazine. Total leukocyte numbers were determined by a particle counter and size analyzer (Z2; Beckman Coulter, Brea, CA, U.S.A.) after treatment with ACK lysis buffer $\left(0.15 \mathrm{M} \mathrm{NH}_{4} \mathrm{Cl}, 1 \mathrm{~mm} \mathrm{KHCO}_{3}\right.$, $0.1 \mathrm{~mm}$ ethylenediaminetetraacetic acid disodium salt, $\mathrm{pH} 7.2$ ) to remove any contaminating erythrocytes. For differential cell counts, cells were transferred onto a glass slide by centrifugation in a cell settling chamber (Neuro Probe, Gaithersburg, MD, U.S.A.). Subsequently, cells were stained with Diff-Quik solution (Sysmex International Reagent, Kobe, Japan).

Terminal Deoxynucleotidyl Transferase (TdT)-Mediated Deoxyuridine Triphosphate (dUTP) Nick-End Labeling (TUNEL) Staining In order to detect apoptotic cells in the epithelium and subepithelial tissue beneath the basement membrane, TUNEL staining was performed. The $4-\mu \mathrm{m} \mathrm{sec}-$ tions prepared as described above was treated with $25 \mu \mathrm{g} /$ $\mathrm{mL}$ protease $\mathrm{K}$ for $30 \mathrm{~min}$ for permeabilization, followed by TUNEL staining using in situ cell death detection kit, POD (Roche Diagnostics, Indianapolis, IN, U.S.A.). The degree of apoptosis in the epithelial cells was quantified: TUNEL-positive cells in the epithelial layer was counted, and the number of positive cells was divided by the length of the basement membrane $(\mu \mathrm{m})$. The numbers of apoptotic cells beneath the basement membrane in area of $220 \times 165 \mu \mathrm{m}^{2}$ were counted under the microscope with $\times 400$ magnification, and expressed as cells/high power field.

Statistical Analyses One-way analysis of variance
(ANOVA) was performed. If significant differences were detected, individual group differences were determined by Bonferroni's multiple test. A probability value $(p)$ below 0.05 was considered significant.

\section{RESULTS}

Development of Airway Remodeling As previously demonstrated by us, ${ }^{9)}$ infiltration of leukocytes and epithelial thickening were clearly observed in the tissue isolated $72 \mathrm{~h}$ after the 3rd challenge (Fig. 1B) in comparison with histology of the lung tissue isolated prior to the 1st challenge (Fig. 1A). Quantitative analyses showed that the degree of epithelial thickening (epithelial area/length of the basement membrane) almost doubled after three intratracheal antigen challenges (Fig. 1E). PAS-staining tissue revealed that mucus glycopro-

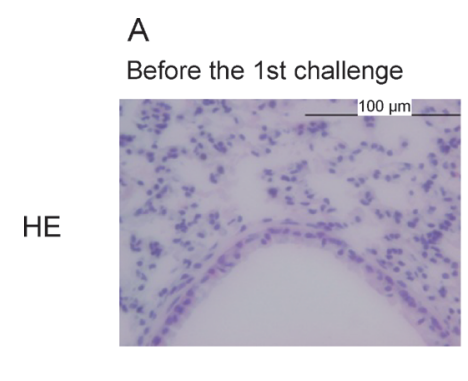

B
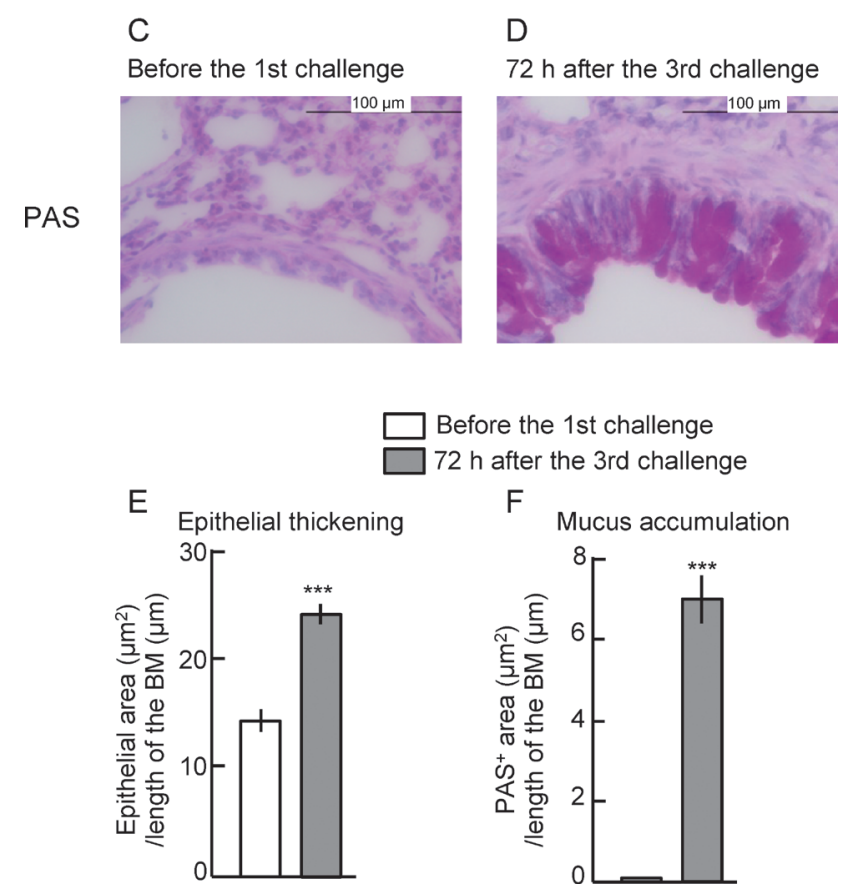

Fig. 1. Development of Airway Remodeling by Multiple Intratracheal Antigen Challenges in Sensitized Mice

BALB/c mice were sensitized by i.p. injection of ovalbumin $(\mathrm{OVA})+\mathrm{Al}(\mathrm{OH})_{3}$ on day 0,14 and 28, and then challenged by intratracheal administration of OVA solution on day 35,36 and 37 . The lungs isolated before the 1 st challenge and $72 \mathrm{~h}$ after the 3 rd challenge were fixed with $10 \%$ formalin, embedded in paraffin, and cut into $4-\mu \mathrm{m}$ sections. Then, hematoxylin and eosin stain (HE, A, B), and periodic acid-Schiff stain (PAS, C, D) were carried out. Degree of epithelial thickening was quantified using PAS-stained sections by dividing epithelial area in a bronchus (diameter: around $200-400 \mu \mathrm{m})$ by the length of basement membrane (BM) (E). Degree of mucus accumulation was calculated by dividing $\mathrm{PAS}^{+}$area in a bronchus by the length of BM (F). Each column in panels $E$ and $F$ represents the mean \pm S.E. of 4 (before the 1st challenge) and 18 ( $72 \mathrm{~h}$ after the 3 rd challenge) animals. The numbers of bronchus used for the measurement of parameters were 4 (before the 1st challenge) and 5 ( $72 \mathrm{~h}$ after the 3 rd challenge) bronchi/animal in average. $* * * p<0.001, v s$. before the 1 st challenge. 
tein had markedly accumulated in the thickened epithelium at $72 \mathrm{~h}$ after the $3 \mathrm{rd}$ challenge in comparison with the tissue isolated before the 1st challenge (Figs. 1C, 1D, 1F).

Effect of MnTBAP on the Development of Airway Remodeling When MnTBAP (3 and $10 \mathrm{mg} / \mathrm{kg} / \mathrm{time}$, i.p.) was daily administered twice a day during the multiple antigen challenges and for subsequent $3 \mathrm{~d}$, body weight was not significantly decreased in comparison with PBS-treated group. The treatment with MnTBAP dose-dependently suppressed the development of multiple antigen challenge-induced epithelial thickening (Figs. 2A-C, G) and mucus accumulation in the epithelial layer (Figs. 2D-F, H). Inhibition on the epithelial thickening and mucus accumulation by $10 \mathrm{mg} / \mathrm{kg} / \mathrm{time}$ MnTBAP were both statistically significant, and the inhibitory degrees were more than $50 \%$ (Figs. $2 \mathrm{G}, \mathrm{H}$ ).

We have reported that the multiple antigen challenge induced lung fibrosis especially around the subepithelial area." Development of the lung fibrosis was not affected by the treatment with MnTBAP (data not shown).

Effect of MnTBAP on the Development of Airway Leukocyte Inflammation As has been reported, ${ }^{9-11)}$ the mul- tiple antigen challenges markedly increased the numbers of mononuclear cells, eosinophils and neutrophils in BALF (Figs. $3 \mathrm{~A}-\mathrm{C}$ ). The daily treatment with MnTBAP did not affect the increases in mononuclear cells and eosinophils (Figs. 3D,E), whereas the increase in neutrophils was augmented by the treatment with $10 \mathrm{mg} / \mathrm{kg} /$ time MnTBAP (Fig. 3F).

Increase in Apoptotic Cells in the Epithelium and Subepithelial Tissue Figures $4 \mathrm{~A}$ and $\mathrm{B}$ show increased number of TUNEL staining-positive apoptotic cells in the lung tissue by the multiple antigen challenges. In comparison with the level at the time prior to the 1st challenge (Fig. 4A), there were a lot of numbers of apoptotic cells in the lung at $72 \mathrm{~h}$ after the 3rd challenge (Fig. 4B). As shown in Fig. 4C, the number of apoptotic cells in the epithelial cell layer was significantly increased by the multiple challenges. The number of apoptotic cells beneath the basement membrane was also increased by the multiple antigen challenges (Fig. 4D).

Effect of MnTBAP on the Increases in Apoptotic Cells As shown in Figs. 4E-G, the daily treatment with MnTBAP $(10 \mathrm{mg} / \mathrm{kg} / \mathrm{time})$ significantly suppressed the multiple antigen challenge-induced increase in apoptotic cells in the epithelial
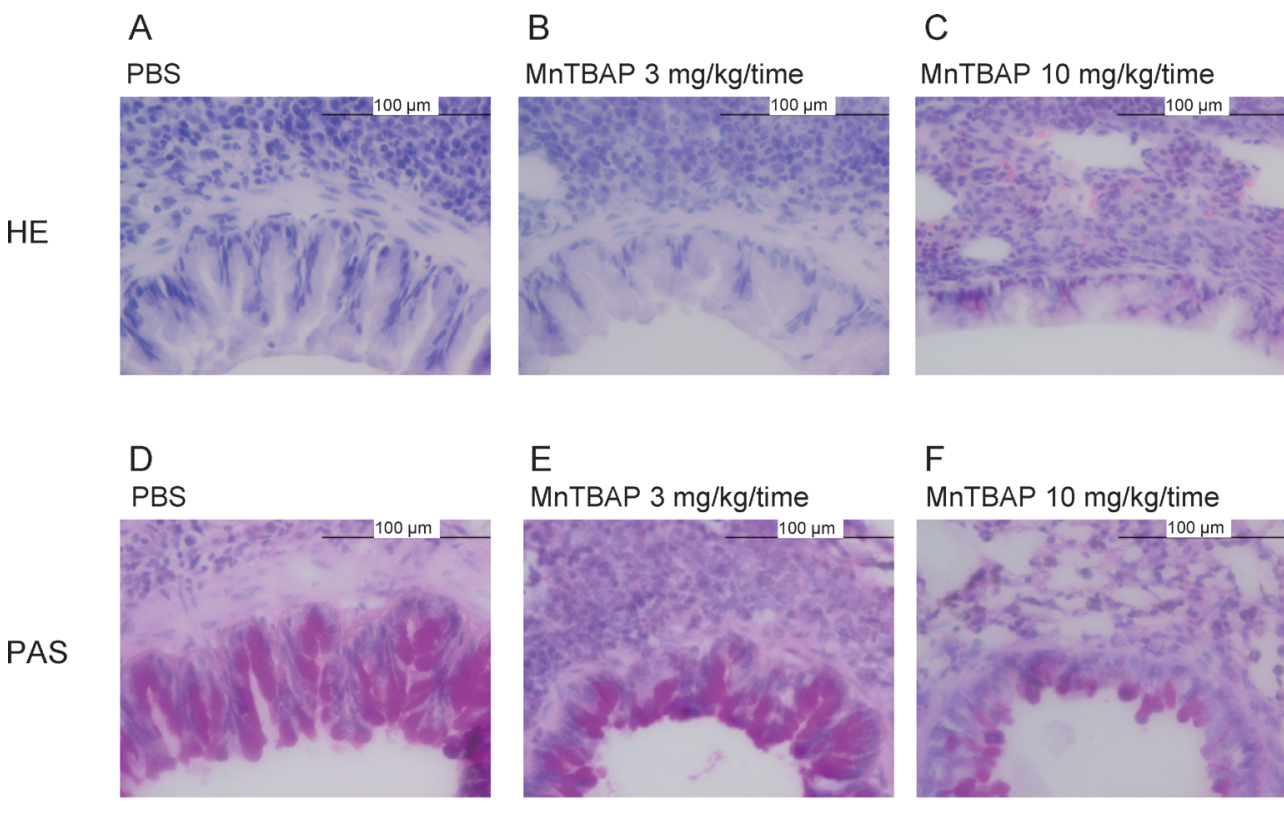

F MnTBAP $10 \mathrm{mg} / \mathrm{kg} / \mathrm{time}$
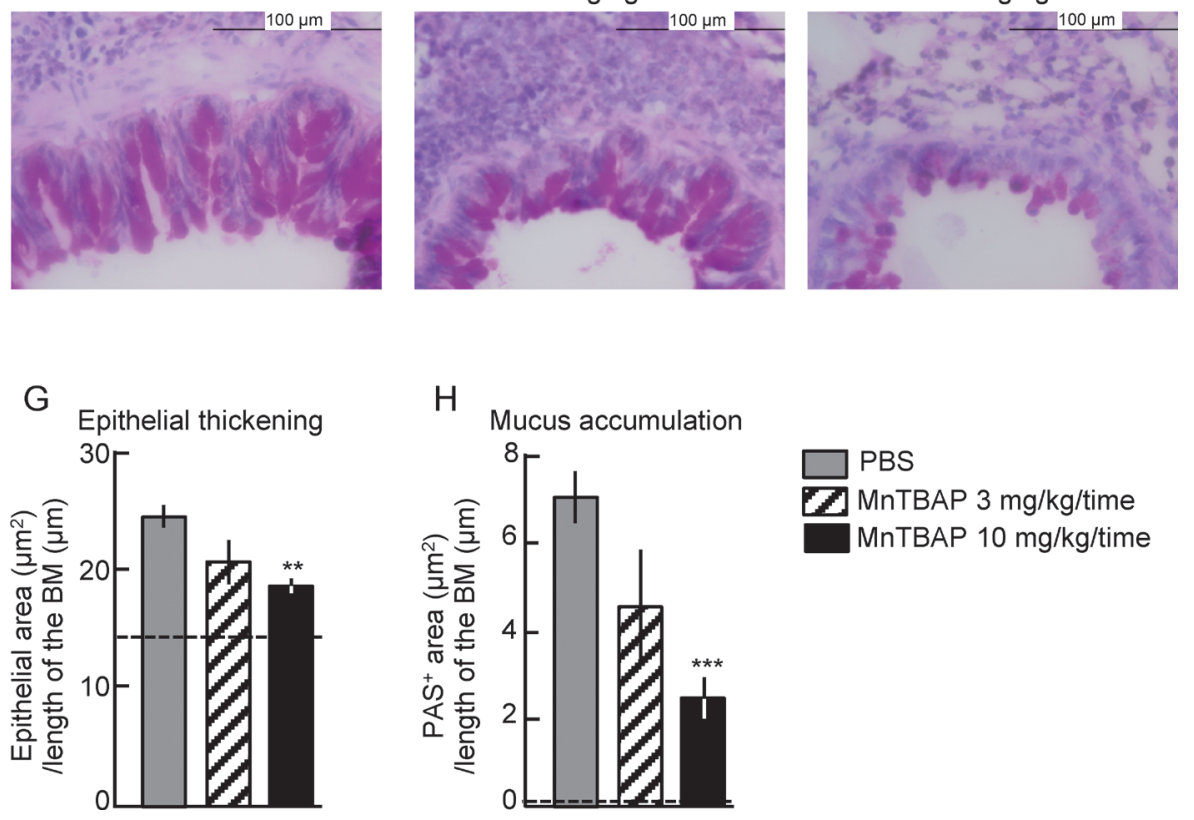

Fig. 2. Effect of MnTBAP on the Multiple Antigen Challenge-Induced Increase in Epithelial Thickness (A-G) and Mucus Accumulation in the Epithelial Layer (D-H) in Sensitized Mice

MnTBAP (3, $10 \mathrm{mg} / \mathrm{kg} / \mathrm{time})$ or PBS was i.p. administered twice daily from the day of the 1st challenge until $72 \mathrm{~h}$ after the $3 \mathrm{rd}$ challenge. Dotted lines represent mean values at the time before the 1st challenge as shown in Figs. 1E and F. Each column represents the mean \pm S.E. of 10-18 animals. The numbers of bronchus used for the measurement of parameters were 5 (PBS), $6(3 \mathrm{mg} / \mathrm{kg} / \mathrm{time} \mathrm{MnTBAP})$ and $7(10 \mathrm{mg} / \mathrm{kg} / \mathrm{time} \mathrm{MnTBAP})$ bronchi/animal in average. $* *$ and $* * * p<0.01$ and $0.001, v s$. PBStreated group. 


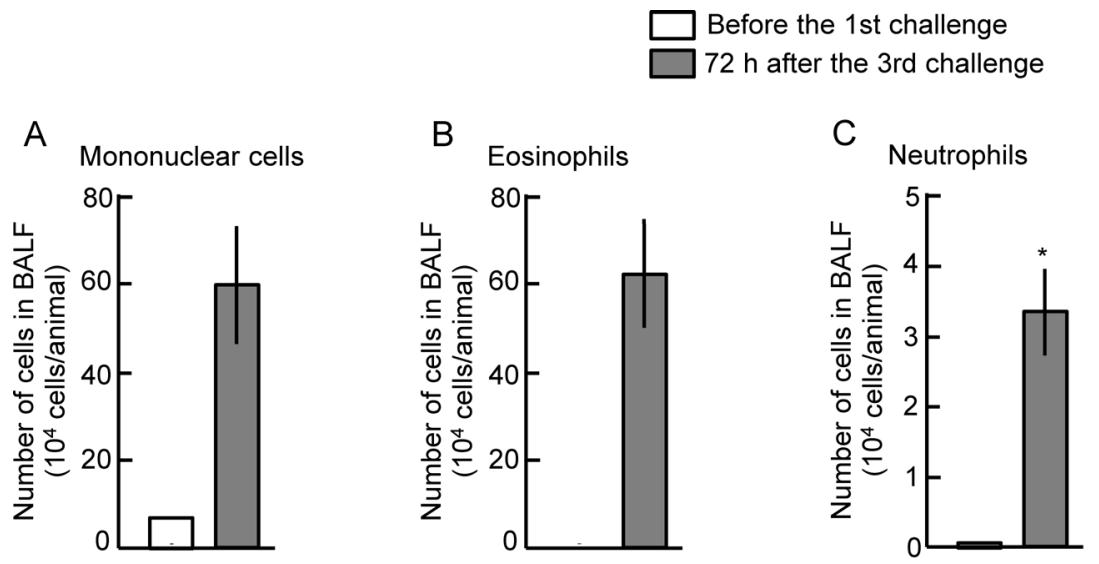

$\mathrm{D}$

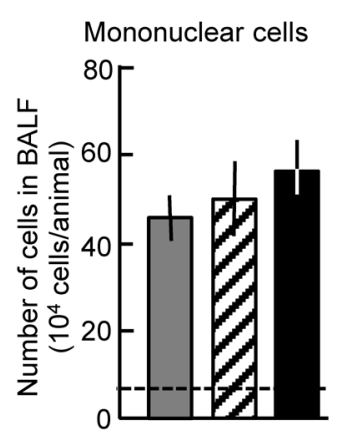

E

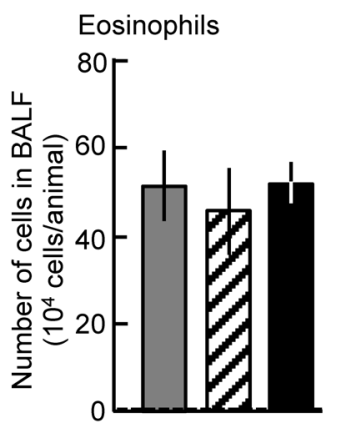

PBS

MnTBAP $3 \mathrm{mg} / \mathrm{kg} / \mathrm{time}$

MnTBAP $10 \mathrm{mg} / \mathrm{kg} / \mathrm{time}$

$\mathrm{F}$

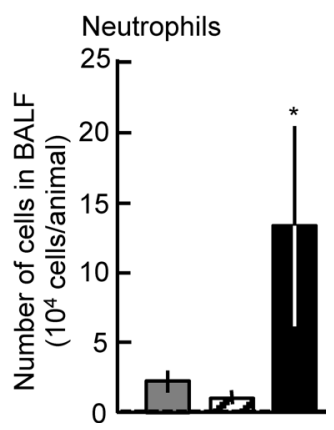

Fig. 3. Increase in Numbers of Leukocytes in Bronchoalveolar Lavage Fluid (BALF) by Multiple Intratracheal Antigen Challenges in Sensitized Mice (A-C), and Effect of MnTBAP on the Cellular Inflammation (D-F)

BAL was performed before the 1 st challenge and $72 \mathrm{~h}$ after the $3 \mathrm{rd}$ challenge. MnTBAP $(3,10 \mathrm{mg} / \mathrm{kg} / \mathrm{time})$ or PBS was i.p. administered twice daily from the day of the 1st challenge until $72 \mathrm{~h}$ after the 3 rd challenge. Dotted lines in panels D, E and F represent mean values at the time before the 1st challenge as shown in panels A, B and C. Each column represents the mean \pm S.E. of 4 (before the 1 st challenge), 14 ( $72 \mathrm{~h}$ after the $3 \mathrm{rd} \mathrm{challenge),10} \mathrm{(PBS),} 4$ (3 mg/kg/time MnTBAP) and 3 (10 mg/kg/time MnTBAP) animals. ${ }^{*} p<0.05$, vs. before the 1 st challenge, or $v s$. PBS-treated group.

cells by approximately $40 \%$ (Fig. 4G). The increase in apoptosis cells beneath the basement membrane was also significantly suppressed by the treatment with MnTBAP (Fig. 4H).

\section{DISCUSSION}

A peroxynitrite scavenger, MnTBAP effectively suppressed the multiple antigen challenge-induced bronchial epithelial thickening and mucus accumulation in the epithelium. Thus, it was strongly suggested that peroxynitrite was involved in the development of the airway remodeling process. Although it was reported that treatment with an anti-oxidant, vitamin E suppressed airway remodeling in a murine asthma model, ${ }^{18)}$ to our knowledge, it is the first report to demonstrate that a peroxynitrite scavenger showed inhibition of airway remodeling in asthma.

There was a greater level of apoptotic cells in the airway of severe asthma patients as compared with normal subjects. ${ }^{8)}$ Consistent with the clinical finding, ${ }^{8)}$ repeated antigen challenge induced apoptosis of airway epithelial cells in murine asthma models as well. ${ }^{19,20)}$ In this study, multiple antigen challenges increased the number of apoptotic cells in the lung, and that the increase in epithelial cell apoptosis was effective- ly suppressed by the MnTBAP treatment. Considering the fact that peroxynitrite is capable of inducing apoptosis of various cells, ${ }^{7)}$ peroxynitrite was possibly involved in the development of airway remodeling by inducing apoptosis of the airway epithelial cells. Once the epithelial cells are injured, new proliferation of epithelial cells should be induced to recover the tissue. ${ }^{4)}$ Excessive apoptosis of epithelial cells may lead to excessive proliferation of epithelial cells, probably resulting in the epithelial thickening and mucus accumulation. Indeed, increased cellular proliferation in the airway contributed to a thickened epithelium in asthmatic patients. ${ }^{8)}$ In the present study, MnTBAP possibly attenuated the vicious circle.

MnTBAP significantly suppressed apoptosis of not only epithelial cells but also cells existing beneath the basement membrane, which consist mainly of leukocyte infiltrated into the alveolar spaces. The inhibition of apoptosis of leukocytes may be related to the increase in the number of neutrophils in brochoalveolar lavage fluid (BALF). These results imply that neutrophils are involved in resolution of the epithelial thickening. However, we have data that neutrophil depletion by an anti-Gr-1 monoclonal antibody could not affect the remodeling (unpublished data), suggesting that the increased neutrophils are not associated with the suppression of epithelial remod- 
A

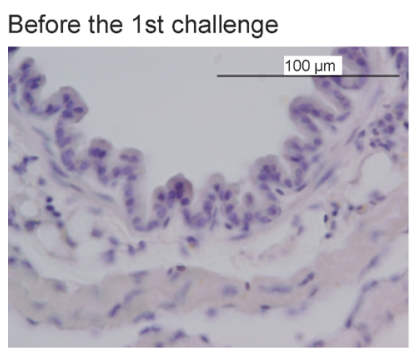

B

$72 \mathrm{~h}$ after the $3 \mathrm{rd}$ challenge

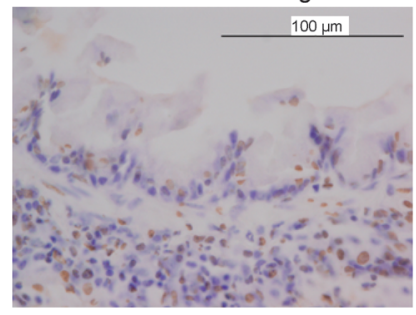

E

PBS

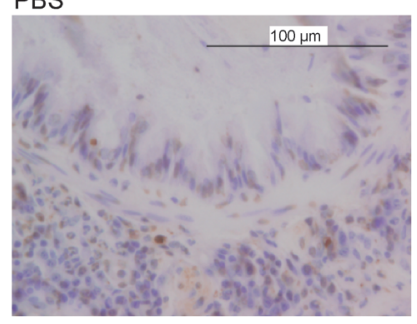

PBS

Before the 1st challenge

$72 \mathrm{~h}$ after the $3 \mathrm{rd}$ challenge

C Apoptosis of epithelial cells

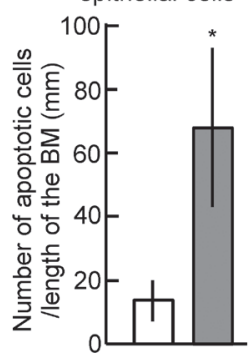

D Apoptosis of cells beneath the BM

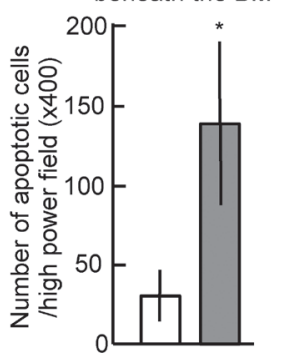

G Effect of MnTBAP on apoptosis of epithelial cells

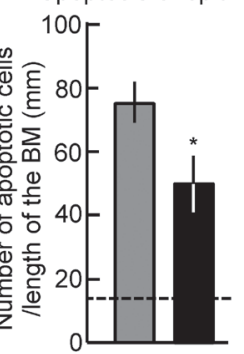

$\mathrm{F}$

MnTBAP $10 \mathrm{mg} / \mathrm{kg}$

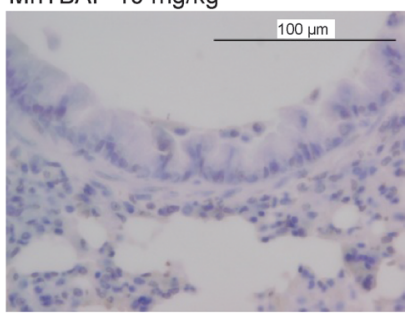

Fig. 4. Increase in Numbers of Apoptotic Cells in the Bronchial Epithelium (A-C) and in Subepithelial Tissue Beneath the Basement Membrane (A, B, D) by Multiple Intratracheal Antigen Challenges in the Sensitized Mice, and Effect of MnTBAP on the Increases (E-H)

Four-micrometer sections of the lungs isolated before the 1 st challenge and $72 \mathrm{~h}$ after the 3 rd challenge were incubated with protease K solution, followed by TUNEL staining. Numbers of apoptotic cells in the epithelium around the bronchus, the diameter of which was $200-400 \mu \mathrm{m}$, were counted under the microscope. The degree of apoptosis was quantified by dividing the number of apoptotic cells by the length of the basement membrane (BM) (C, G). Numbers of apoptotic cells in the subepithelial tissue beneath the BM in area of $220 \times 165 \mu \mathrm{m}^{2}$ were counted under the microscope with $\times 400$ magnification (D, H). Dotted lines in panels $\mathrm{G}$ and $\mathrm{H}$ represent mean values at the time before the 1st challenge as shown in panels $\mathrm{C}$ and D. Each column represents the mean \pm S.E. of 6 (before the 1st challenge), 3 ( $72 \mathrm{~h}$ after the $3 \mathrm{rd}$ challenge), 10 (PBS), and 10 (MnTBAP) animals. The numbers of bronchus used for the measurement of apoptosis of epithelial cells (C, G) were 3 (before the 1st challenge), 3 ( $72 \mathrm{~h}$ after the 3rd challenge), 4 (PBS), and 3 (10 mg/kg MnTBAP) bronchi/animal in average. The numbers of field used for the measurement of apoptotic cells beneath the BM were 5 fields/animal in all groups. ${ }^{*} p<0.05, v s$. before the 1 st challenge, or $v s$. PBS-treated group.

eling by MnTBAP. It may be required to assess effects of MnTBAP on recruitment and activation of cells possessing regulatory function in inflammation because it has been suggested that regulatory $\mathrm{T}$ cells and regulatory dendritic cells may be involved in resolution of asthma pathogenesis. ${ }^{21,22)}$

Cellular sources of nitric oxide (NO) and superoxide anion produced during the antigen challenges are not clear. In this murine model of asthma, eosinophils were progressively infiltrated into the lung by the multiple antigen challenges, ${ }^{9,10)}$ and neutrophils were also increased in the lung after the respective antigen challenges. ${ }^{10,11)}$ Thus, these granulocytes can be considered to be cellular sources of NO and superoxide anion. However, as mentioned above, depletion of only neutrophils did not affect the development of airway remodeling (unpublished data). In addition, we have reported that even when airway eosinophilia was strongly suppressed by treatment with monoclonal antibody against interleukin-5, which is a potent eosinophilopoietic cytokine, no suppression of airway remodeling was observed.9) Thus, neither eosinophils nor neutrophils may be involved in the formation of peroxynitrite and subsequent airway remodeling. However, suppressing only a single type of cells may not be enough for affecting the development of airway remodeling. In our recent preliminary experiments, both M2 (mannose receptor ${ }^{+}$) and M1 (inducible NO synthase $^{+}$) alveolar macrophages were also increased in the lung by the multiple antigen challenges (unpublished data). It has been well known that macrophages can be cellular sources of both NO and superoxide anion. ${ }^{23)}$ Thus, alveolar macrophages may be associated with the complicated mechanisms underly- ing the development of airway remodeling.

In conclusion, the peroxynitrite scavenger, MnTBAP exerted protective action on the development of airway remodeling in asthma. This suppression was closely associated with reduction of apoptosis of epithelial cells. Thus, peroxynitrite can be a target molecule for development of new pharmacotherapy for asthma.

Acknowledgment This study was supported in part by a Grant-in-Aid for Scientific Research (C) (23590093, T. Nabe) from Japan Society for the Promotion of Science.

\section{REFERENCES}

1) Pascual RM, Peters SP. Airway remodeling contributes to the progressive loss of lung function in asthma: an overview. J. Allergy Clin. Immunol., 116, 477-486, quiz, 487 (2005).

2) Sumi Y, Hamid Q. Airway remodeling in asthma. Allergol. Int., 56, 341-348 (2007)

3) Holgate ST. Innate and adaptive immune responses in asthma. Nat. Med., 18, 673-683 (2012).

4) Lambrecht BN, Hammad H. The airway epithelium in asthma. Nat. Med., 18, 684-692 (2012).

5) ten Hacken NH, van der Vaart H, van der Mark TW, Koëter GH, Postma DS. Exhaled nitric oxide is higher both at day and night in subjects with nocturnal asthma. Am. J. Respir. Crit. Care Med., 158, 902-907 (1998).

6) Antczak A, Nowak D, Shariati B, Król M, Piasecka G, Kurmanowska Z. Increased hydrogen peroxide and thiobarbituric acid-reactive products in expired breath condensate of asthmatic patients. Eur. 
Respir. J., 10, 1235-1241 (1997).

7) Pacher P, Beckman JS, Liaudet L. Nitric oxide and peroxynitrite in health and disease. Physiol. Rev., 87, 315-424 (2007).

8) Cohen L, E X, Tarsi J, Ramkumar T, Horiuchi TK, Cochran R, DeMartino S, Schechtman KB, Hussain I, Holtzman MJ, Castro M. Epithelial cell proliferation contributes to airway remodeling in severe asthma. Am. J. Respir. Crit. Care Med., 176, 138-145 (2007).

9) Nabe T, Morishita T, Matsuya K, Ikedo A, Fujii M, Mizutani N, Yoshino S. Complete dependence on CD4+ cells in late asthmatic response, but limited contribution of the cells to airway remodeling in sensitized mice. J. Pharmacol. Sci., 116, 373-383 (2011).

10) Nabe T, Zindl CL, Jung YW, Stephens R, Sakamoto A, Kohno S, Atkinson TP, Chaplin DD. Induction of a late asthmatic response associated with airway inflammation in mice. Eur. J. Pharmacol., 521, 144-155 (2005).

11) Nabe T, Hosokawa F, Matsuya K, Morishita T, Ikedo A, Fujii M, Mizutani N, Yoshino S, Chaplin DD. Important role of neutrophils in the late asthmatic response in mice. Life Sci., 88, 1127-1135 (2011).

12) Henderson WR Jr, Tang LO, Chu SJ, Tsao SM, Chiang GK, Jones F, Jonas M, Pae C, Wang H, Chi EY. A role for cysteinyl leukotrienes in airway remodeling in a mouse asthma model. Am. J. Respir. Crit. Care Med., 165, 108-116 (2002).

13) Ohta S, Oda N, Yokoe T, Tanaka A, Yamamoto $Y$, Watanabe $Y$, Minoguchi K, Ohnishi T, Hirose T, Nagase H, Ohta K, Adachi M. Effect of tiotropium bromide on airway inflammation and remodelling in a mouse model of asthma. Clin. Exp. Allergy, 40, 1266-1275 (2010).

14) Batinić-Haberle I, Cuzzocrea S, Rebouças JS, Ferrer-Sueta G, Mazzon E, Di Paola R, Radi R, Spasojević I, Benov L, Salvemini D. Pure MnTBAP selectively scavenges peroxynitrite over superoxide: comparison of pure and commercial MnTBAP samples to MnTE-2-PyP in two models of oxidative stress injury, an SOD- specific Escherichia coli model and carrageenan-induced pleurisy. Free Radic. Biol. Med., 46, 192-201 (2009).

15) Rebouças JS, Spasojević I, Batinić-Haberle I. Quality of potent Mn porphyrin-based SOD mimics and peroxynitrite scavengers for preclinical mechanistic/therapeutic purposes. J. Pharm. Biomed. Anal., 48, 1046-1049 (2008).

16) Oury TD, Thakker K, Menache M, Chang LY, Crapo JD, Day BJ. Attenuation of bleomycin-induced pulmonary fibrosis by a catalytic antioxidant metalloporphyrin. Am. J. Respir. Cell Mol. Biol., 25, 164-169 (2001).

17) Ho W, Furst A. Intratracheal instillation method for mouse lungs. Oncology, 27, 385-393 (1973).

18) Mabalirajan U, Aich J, Leishangthem GD, Sharma SK, Dinda AK, Ghosh B. Effects of vitamin E on mitochondrial dysfunction and asthma features in an experimental allergic murine model. J. Appl. Physiol., 107, 1285-1292 (2009).

19) Truong-Tran AQ, Ruffin RE, Foster PS, Koskinen AM, Coyle P, Philcox JC, Rofe AM, Zalewski PD. Altered zinc homeostasis and caspase-3 activity in murine allergic airway inflammation. Am. J. Respir. Cell Mol. Biol., 27, 286-296 (2002).

20) Dorscheid DR, Low E, Conforti A, Shifrin S, Sperling AI, White SR. Corticosteroid-induced apoptosis in mouse airway epithelium: effect in normal airways and after allergen-induced airway inflammation. J. Allergy Clin. Immunol., 111, 360-366 (2003).

21) Akdis CA, Akdis M. Mechanisms and treatment of allergic disease in the big picture of regulatory T cells. J. Allergy Clin. Immunol., 123, 735-746, quiz, 747-748 (2009).

22) Akbari O, Umetsu DT. Role of regulatory dendritic cells in allergy and asthma. Curr. Opin. Allergy Clin. Immunol., 4, 533-538 (2004).

23) Xia Y, Zweier JL. Superoxide and peroxynitrite generation from inducible nitric oxide synthase in macrophages. Proc. Natl. Acad. Sci. U.S.A., 94, 6954-6958 (1997). 